\title{
VARIOS
}

\section{Nuevas Técnicas de Docencia}

\author{
Dr. Arturo Aparicio Laserna
}

\section{INTRODUCCION}

Firmemente convencido de los acelerados adelantos de la ciencia médica, del desarrollo constante de nuevas teorías y de la evolución permanente de las técnicas quirúrgicas, el médico en general y en especial el recién egresado, deben buscar en las revistas de información médica la manera de actualizar sus conocimientos.

Pero es tal la cantidad de éstas, que es casi imposible consultarlas a todas, de donde han resultado nuevos modelos especializados que resumen artículos y los reagrupan por temas. De ésta manera el médico ahorra tiempo y puede revisar un mayor número de problemas médicos interesantes.

Personalmente estoy convencido del alto nivel médico y académico de la Medicina Colombiana, ya que tuvimos la fortuna de heredar en parte la Escuela Francesa de los grandes clínicos y observadores del paciente, en la cual se daba más importancia, para el diagnóstico correcto, a todos aquellos datos que el enfermo nos pueda suministrar como unidad individual y no como resultante de un frío'análisis estadístico.
Nuestra medicina cambió bastante en la post-guerra recibiendo un gran influjo de la norteamericana, en la cual son fundamentales las sofisticadas técnicas de laboratorio y la Bio-ingeniería Médica, con analizadores computarizados que por exactos que sean, se tornan fríos y pierden el calor humano, dejando muchas veces de lado las angustias y temores del paciente sobre los cuales el médico consciente debe saber influir.

Pero si bien es cierto que todas estas técnicas modernas no son viables en un país en vía de desarrollo como el nuestro por sus altos costos de funcionamiento, no podemos desecharlas y antes bien debemos tratar de imitarlas y asimilarlas, de acuerdo con nuestros escasos recursos.

En nuestro medio hemos sido testigos de la abnegada labor de nuestros cirujanos en el medio hospitalario; de sus profundos conocimientos y de sus refinadas técnicasquirúrgicas aprovechadas tan sólo por un grupo muy escaso de asistentes pero que no trascienden al resto de estudiantes ni al conglomerado médico del país. Siendo además, su labor docente-asistencial, es casi humanamente imposible por el cálculo de trabajo individual, preparar, estudiar 
y publicar artículos casi a diario, de sus conocimientos $y$ experiencias.

De aquí nuestro gran anhelo de difunfir entre nuestros colegas el novedoso método de la VIDEO-GRABACION, objeto de nuestro trabajo. De ésta manera, el cirujano sin pérdida de tiempo y durante el acto operatorio, podrá dar una pequeña conferencia sobre la entidad en tratamiento; sobre su etiología; sus posibles conductas e ir explicando, paso a paso, la técnica operatoria en curso.

Posteriormente la OFICINA DE ME. DIO AUDIOVISUALES de la Universidad o del Hospital, se encargará de elaborar los bosquejos $\mathrm{y}$ créditos necesarios para una ulterior edición de la película, previo el visto bueno del Cirujano tratante. Una vez. editada la cinta quedará bajo la responsabilidad de la Oficina Central o VIDEOTE. CA de la organización, prestando un invaluable servicio a estudiantes, internos, residentes, etc. a quienquiera consultarlas.

Con éste sencillo método se puede borrar, repetir escenas no bien filmadas $y$ sacar cuantas copias sean requeridas por el cirujano.

Hoy en día, todos aceptamos el hecho de que los medios audiovisuales ocupan primerísima línea entre los métodos de enseñanza universitaria, sin olvidar que, en medicina, no debemos ignorar el contacto individual y la transferencia casi inconsciente que debe existir entre médico y paciente.

En Estados Unidos este sistema de enseñanza ha tenido un auge extraordinario, a tal punto, que por una depurada técnica de comunicación vía satélite a través de la
"PORTABLE EARTH TERMINAL" de la NASA, intercomunican Hospitales de cuatro a cinco Estados de tal suerte que por medio de televisión pueden consultarse simultáneamente. Mediante grabación electro-magnética, todas las conferencias importantes que se desarrollan en cualquiera de los Hospitales en circuito, quedan grabadas y a disposición de quien quiera consultarlas. Estos equipos van, desde los grandes aparatos profesionales de las centrales de televisión; los equipos Semi-Profesionales como el U. MATIC o el VHS de 270 líneas de definición hasta los simples equipos caseros BETAMAX de 240 líneas de definición, usados por no sotros.

La técnica de grabación, edición y reproducción de éstos equipos es bien sencilla y elemental, aun cuando en un principio podamos tener alguna falla que fácilmente pueda ser corregida por un técnico, de tal suerte que en poco tiempo pueda ser manejado por el médico interesado.

Los costos día a día se abaratan y su manejo se simplifica. En la cinta que proyectamos se utilizó una filmadora PANASONIC PVC 300, ya pasada de moda, por cuanto es hacer el balance "del blan$\mathrm{Co}^{\prime \prime}$ manualmente por lo cual veremos en la película interferir cuando trabajamos sobre campos blancos. La intensidad lumínica deforma el color e interfiere con el sonido.

EI nuevo modelo PANASONIC PVC 3.300 integra y balancea el blanco electrónicamente, de tal suerte que las áreas luminosas no se sobresaturan y no se deforman el sonido. 
Mi gran propósito al presentar éste trabajo es el de fomentar en todos los Hospitales Universitarios la creacción o mejoramiento de las VIDEOTECAS MEDICAS, que prestarán a no dudarlo, invaluables servicios tanto al estudiantado como a los médicos en general.
Al terminar ésta presentación, quedaría ampliamente recompensado al haber despertado entre mis colegas la afición por éstas disciplinas y el haber demostrado cómo, con escasos recursos, se puede realizar una VIDEOGRABACION, de gran utilidad para la enseñanza médica. 